\title{
Green synthesis and characterization of cuprous oxide nanoparticles in presence of a bio-surfactant
}

\author{
M. BEHERA*, G. GIRI \\ Silicon Institute of Technology, Silicon Hills, Bhubaneswar, Odisha-751 024, India
}

\begin{abstract}
Herein, we report a facile green synthesis of $\mathrm{Cu}_{2} \mathrm{O}$ nanoparticles (NPs) using copper sulfate as precursor salt and hydrazine hydrate as reducing agent in presence of bio-surfactant (i.e. leaves extract of arka - a perennial shrub) at 60 to $70{ }^{\circ} \mathrm{C}$ in an aqueous medium. A broad band centered at $460 \mathrm{~nm}$ in absorption spectrum reveals the formation of surfactant stabilized $\mathrm{Cu}_{2} \mathrm{O}$ NPs. X-ray diffraction pattern of the surfactant stabilized NPs suggests the formation of only $\mathrm{Cu}_{2} \mathrm{O}$ phase in assistance of a bio-surfactant with the crystallite size of $\sim 8 \mathrm{~nm}$. A negative zeta potential of $-12 \mathrm{mV}$ at $8.0 \mathrm{pH}$ in surfactant stabilized $\mathrm{Cu}_{2} \mathrm{O}$ NPs hints non-bonding electron transfer from O-atom of saponin to the surface of NP. Red-shift in the vibrational band $\left(\mathrm{Cu}-\mathrm{O}\right.$ stretching) of $\mathrm{Cu}_{2} \mathrm{O}$ from $637 \mathrm{~cm}^{-1}$ to $640 \mathrm{~cm}^{-1}$ in presence of bio-surfactant suggests an interfacial interaction between $\mathrm{NPs}$ and $\mathrm{O}$-atoms of $-\mathrm{OH}$ groups of saponin present in the plant (i.e. Calotropis gigantea) extract. From X-ray photoelectron spectroscopy spectra, a decrease in binding energy of both $2 \mathrm{p}_{3 / 2}$ and $2 \mathrm{p}_{1 / 2}$ bands in $\mathrm{Cu}_{2} \mathrm{O}$ with saponin molecules as compared to bulk $\mathrm{Cu}$ atom reveals a charge transfer interaction between NP and saponin surfactant molecules. Transmission electron microscopy images show crystalline nature of $\mathrm{Cu}_{2} \mathrm{O}$ NPs with an fcc lattice.
\end{abstract}

Keywords: green synthesis; transition metal oxide; bio-surfactant; zeta potential; charge transfer

(C) Wroclaw University of Technology.

\section{Introduction}

Synthesis of nanostructured transition metal oxides (TMOs), such as zinc oxide, copper oxides, titanium oxide, etc., are of significant technological interest owing to their superb catalytic activity, excellent gas sensing ability, outstanding antibacterial/antimicrobial activity, easy availability of cheap and up-scalable synthetic routes, high thermal conductivity, and non-toxicity [1-4]. Among various TMOs, production of cuprous oxide $\left(\mathrm{Cu}_{2} \mathrm{O}\right)$ nanoparticles (NPs) is of special attention not only in the scientific field but also in industry, due to numerous applications, such as photo catalysis, [1-5] solar cells [1,5], anti-fouling coatings [5] gas sensing [4, 6, 7], super conductivity [7], magnetic storage devices [4, 8], and anti-bacterial agent $[4,9]$. Usually, two production methods: from gas-phase and from liquid-phase are widely tested for copper based oxide NPs. However, the wet chemical reduction route, mainly

*E-mail: mano.silicon@gmail.com in presence of an encapsulating agent, seems to be superior to the first one as it produces highly dispersible NPs at low reaction temperature [2]. The use of suitable capping/stabilizing agent is of paramount importance not only in the synthesis of NPs with respect to nucleation and growth processes but also in post-synthesis phenomenon, like aggregation/agglomeration in any liquid media.

Among the various stabilizing agents, natural surfactant molecules, such as saponins, which are found in plant extracts of both dicotyledonous and monocotyledonous plants are used as efficient stabilizing agents not only due to their amphiphilic nature but also due to rich biological activity and physiochemical properties [10]. In addition, these natural surface active agents are found to be vital components in vaccines, food supplements, soft drinks, anti-aging creams, and cosmetics [10]. Saponin in food decreases the cholesterol level in blood and lowers the risk of heart diseases.

In this report, we discuss green synthesis of $\mathrm{Cu}_{2} \mathrm{O}$ NPs in presence of plant (i.e. Calotropis gigantea) extract, which contains saponin that is used 
as a stabilizing agent and hydrazine hydrate as a reducing agent, in an aqueous medium. The synthesized nanopowders were characterized using UVVis, Fourier transform infrared (FT-IR), X-ray photoelectron spectroscopy (XPS), X-ray diffraction (XRD), zeta potential measurements, and transmission electron microscopy (TEM).

\section{Experimental}

\subsection{Synthesis of $\mathrm{Cu}_{2} \mathrm{O}$ NPs}

In a typical wet chemical route, at first, required amount of precursor copper sulphate $\left(\mathrm{CuSO}_{4} \cdot 5 \mathrm{H}_{2} \mathrm{O}\right)$ crystals was added to double distilled water to get $1 \mathrm{M}$ solution. An aqueous plant extract was made by adding about $10 \mathrm{~g}$ of arka leaf to $100 \mathrm{~mL}$ water into a conical flask and was boiled for $1 \mathrm{~h}$ on a hot plate. Then, the two solutions were mixed in a proper ratio and stirred in a magnetic stirrer for half an hour at $70{ }^{\circ} \mathrm{C}$. Under the stirring condition, hydrazine hydrate reducing agent was added dropwise till the blue color (due to $\mathrm{Cu}^{2+}$ ions) changed into a permanent reddish-brown suspension consisting of cuprous oxide $\left(\mathrm{Cu}_{2} \mathrm{O}\right)$ NPs as a dispersed phase. The colloids, thus, obtained were kept standstill overnight to settle down $\mathrm{Cu}_{2} \mathrm{O}$ NPs. After careful pouring out the upper supernatant solution, the wet solid particles were kept in an electrical oven at $80^{\circ} \mathrm{C}$ for $2 \mathrm{~h}$ to get completely dried $\mathrm{Cu}_{2} \mathrm{O}$ powder samples. To confirm the formation of $\mathrm{Cu}_{2} \mathrm{O}$ NPs, $2 \mathrm{~mL}$ of a concentrated ammonia solution was added to $10 \mathrm{mg} \mathrm{Cu}_{2} \mathrm{O}$ powders taken in a $25 \mathrm{~mL}$ beaker. Formation of a clear blue solution of $\left[\mathrm{Cu}\left(\mathrm{NH}_{3}\right)_{4}\left(\mathrm{H}_{2} \mathrm{O}\right)_{2}\right]^{2+}$ complex indicated formation of copper (I) oxide [11]. The dried samples were kept in desiccators for characterizations.

\subsection{Characterization techniques}

UV-Vis absorption spectra were acquired on a Perkin-Elmer spectrophotometer. The crystal phase of synthesized NPs was identified using an X-ray diffractometer (Rigaku D/Max 2000). Vibrational spectra of the powder samples were studied with a Thermo Nicolet Corporation FT-IR Spectrometer (Model NEXUS-870). X-ray photoelectron spectrum (XPS) was collected on a VG ESCALAB
MK-II spectrometer with a monochromatic $\mathrm{Al} \mathrm{K} \alpha$ source $(\mathrm{h} v=1486.6 \mathrm{eV})$ operated at $10 \mathrm{kV}$ and $20 \mathrm{~mA}$ at $10^{-9} \mathrm{~Pa}$. A sample for XPS was prepared by drop-casting a drop of aqueous dispersion of $\mathrm{Cu}_{2} \mathrm{O}$ NPs on silicon substrate and dried in desiccators by keeping overnight at room temperature. Zeta potential was measured with a Malvern Nano ZS instrument using phase analysis light scattering technique. Solid samples were sonicated for $20 \mathrm{~min}$ to well disperse oxide NPs in water prior to measuring zeta potential $(\xi)$ and surface conductivity $\left(\sigma_{s c}\right)$. The dispersed samples were analyzed thrice at $25{ }^{\circ} \mathrm{C}$. Microscopic images of biosurfactantencapsulated GNPs were studied with a high resolution transmission electron microscope (HRTEM) of JEM-2100 (JEOL, Japan) operated at an accelerating voltage of $100 \mathrm{kV}$. The sample was prepared by introduction of only one drop of dispersed specimen on a carbon coated 400-mesh copper grid and then allowing the sample to dry in desiccators overnight at room temperature.

\section{Results and discussion}

\subsection{UV-Vis spectra}

Fig. 1A shows the electronic absorption spectra of $\mathrm{Cu}_{2} \mathrm{O}$ TMO powders: (i) without and (ii) with the plant extract. In the absorption spectra, sample (i) shows two distinct broad bands, one at $\sim 472 \mathrm{~nm}$ and other one at $\sim 715 \mathrm{~nm}$ in the visible range. The first band results from band-to-band transition in $\mathrm{Cu}_{2} \mathrm{O}$ NPs and the second band comes from $\mathrm{CuO}$ NPs [2]. The absence of the second band in sample (ii) in the visible region suggests that bio-surfactant helps in formation of only $\mathrm{Cu}_{2} \mathrm{O}$ phase by acting as a good surface capping agent. The absorption maximum for sample (i) and sample (ii) is centered at 472 and $460 \mathrm{~nm}$, respectively. Broad absorption band in the region 450 to $520 \mathrm{~nm}$, attributed to band-to-band transition, reveals formation of $\mathrm{Cu}_{2} \mathrm{O}$ NPs $[1,2,12,13]$. The position of this band depends mostly on the size, shape, and dielectric environment of the NP. Blue-shift $(\sim 12 \mathrm{~nm})$ in the absorption maximum in presence of plant extract is due to the quantum confinement effects [12-14]. Here, the bio-encapsulating agent 
helps in accumulation of non-bonding electrons of $\mathrm{O}$-atom of $-\mathrm{OH}$ groups of saponin on the surface of $\mathrm{Cu}_{2} \mathrm{O}$.

In order to find the band gap $\left(\mathrm{E}_{g}\right)$ of p-type semiconductor, like $\mathrm{Cu}_{2} \mathrm{O}$ NPs, we have used an equation that shows the relationship between absorption coefficient $(\alpha)$ and photon energy $(\mathrm{h} v)$, which can be expressed as [15]:

$$
\alpha h v=B\left(h v-E_{g}\right)^{\frac{1}{2}}
$$

where $\mathrm{B}$ is a constant, which does not depend upon the photon energy. The $\mathrm{E}_{g}$-value of $\mathrm{Cu}_{2} \mathrm{O}$ nanocrystals can be determined from the intercept of the tangent to the $(\alpha \mathrm{h} v)^{2} v s$. hv graph (Fig. 1B), widely known as Tauc plot. The $\mathrm{E}_{g}$-value, thus, obtained from the plot is $2.36 \mathrm{eV}$. It reveals that this nanocrystal can be activated by visible light $[2,16]$. The blue-shift of nearly $0.16 \mathrm{eV}$ of the $\mathrm{Cu}_{2} \mathrm{O}$ band gap reveals quantum size effect [2].
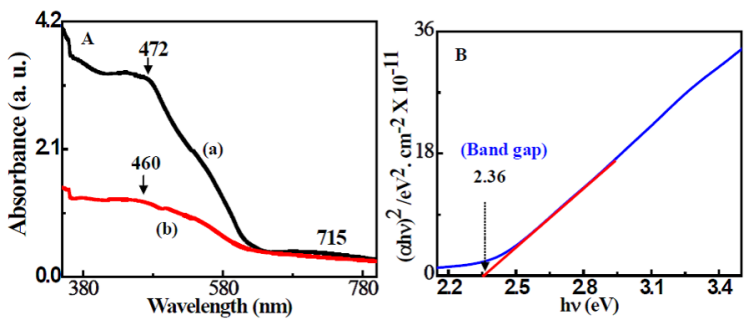

Fig. 1. (A) Absorption spectra of $\mathrm{Cu}_{2} \mathrm{O}$ NPs: (a) with and (b) without plant extract; (B) Tauc plot for $\mathrm{Cu}_{2} \mathrm{O}$ NPs in presence of plant extract.

\subsection{XRD patterns}

Fig. 2 depicts the XRD pattern of $\mathrm{Cu}_{2} \mathrm{O}$ NPs (a) with and (b) without plant extract. According to the JCPDS Card No. 78-2076, the pattern can be indexed as cubic structure $[1,2]$. In Fig. 2(a), the characteristic peaks as observed at $2 \theta$ values of $29.3,36.8,42.3,61.4,73.5$, and $77.6^{\circ}$ are assigned to the crystal planes of (110), (111), (200), (220), (311), and (222) of crystalline $\mathrm{Cu}_{2} \mathrm{O}$, respectively $[1,2]$. As can be seen from Fig. 2(b), it consists of two peaks of $\mathrm{CuO}$ NPs, one at $2 \theta$ values $53.5^{\circ}$ and the other one at $57.5^{\circ}$. The absence of $\mathrm{CuO}$ peaks in presence of bio-surfactant suggests that saponin plays an important role in synthesis of phase pure $\mathrm{Cu}_{2} \mathrm{O}$ NPs. Abboud et al. [4] synthesized copper oxide NPs in presence of a brown alga extract, but they obtained both cuprous and cupric oxide NPs.

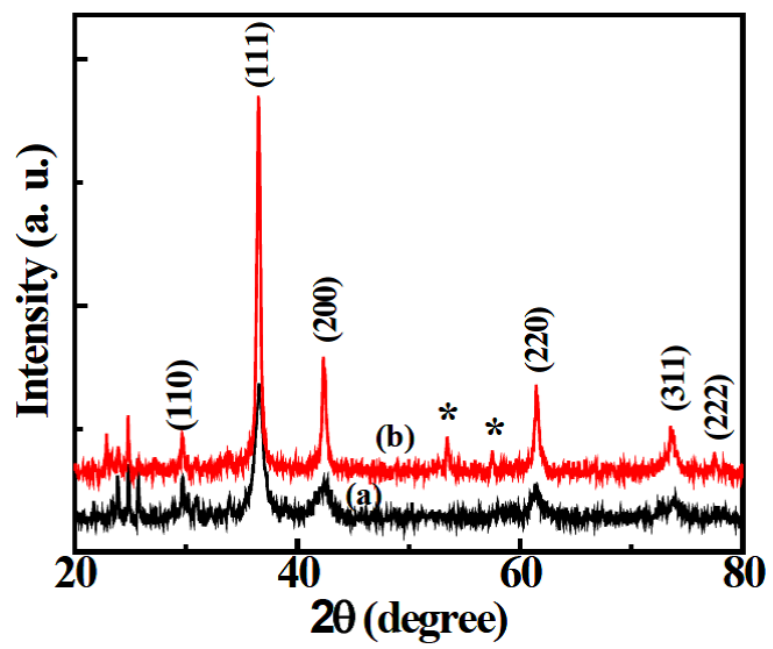

Fig. 2. XRD patterns of $\mathrm{Cu}_{2} \mathrm{O}$ NPs: (a) with and (b) without plant extract.

The crystallite size calculated using DebyeScherer formulae was 17 and $8 \mathrm{~nm}$ for $\mathrm{Cu}_{2} \mathrm{O}$ NPs without and with plant extract, respectively. This result suggests that bio-surfactant reduces the size by acting as encapsulating and size regulating agent.

\subsection{FT-IR spectra}

Vibrational spectra of $\mathrm{Cu}_{2} \mathrm{O}$ powder samples (a) with and (b) without bio-surfactant in the range of 1000 to $500 \mathrm{~cm}^{-1}$ are depicted in Fig. 3. Red-shift of nearly $3 \mathrm{~cm}^{-1}$ in the typical $\mathrm{Cu}-\mathrm{O}$ stretching band in presence of bio-surfactant reveals surface encapsulation of oxide NPs via O-atom of hydroxyl group of one of the major constituent (i.e. saponin) present in the leaf extract of arka (Calotropis gigantea) plant [17-19]. Such interfacial interaction between oxide particles and saponin is vital in enhancing the colloidal stability of aqueous $\mathrm{Cu}_{2} \mathrm{O}$ dispersions.

\subsection{Zeta potential and XPS study}

Fig. 4 displays the distribution of $\xi$-value on the surface of $\mathrm{Cu}_{2} \mathrm{O}$ NPs (a) with and (b) without 


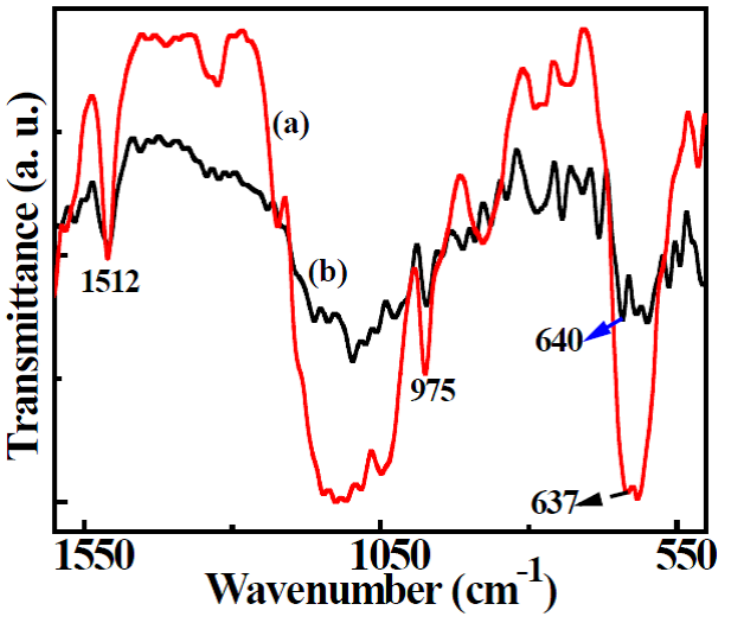

Fig. 3. FT-IR spectra of $\mathrm{Cu}_{2} \mathrm{O}$ NPs: (a) with and (b) without plant extract.

bio-surfactant at $8.0 \mathrm{pH}$. Negative zeta potential represents the presence of negative charge on the surface of oxide NPs. An increase in the average $\xi$ value from $-6 \mathrm{mV}$ to $-12 \mathrm{mV}$ in the presence of bio-surfactant in sample (a) suggests accumulation of nonbonding electrons of $\mathrm{O}$-atoms $(-\mathrm{OH})$ of saponin present in the plant extract $[20,21]$. As it is seen from the inset of Fig. 4, the zeta distribution profile of $\mathrm{Cu}_{2} \mathrm{O}$ NPs with bio-surfactant consists of two overlapping bands, one at $-6.0 \mathrm{mV}$ from $\mathrm{Cu}_{2} \mathrm{O}$ NPs without surfactant and the second band near $-12.0 \mathrm{mV}$ from surfactant capped $\mathrm{Cu}_{2} \mathrm{O}$ NPs. Also the full-width at half maximum for sample (a), which is calculated to be higher $(\sim 11.0 \mathrm{mV})$ as compared to sample (b) $(\sim 8.5 \mathrm{mV})$, further reveals the role of surfactant in augmenting the zeta-value in sample (a).

We also studied variations of zeta potential with $\mathrm{pH}$ of $\mathrm{Cu}_{2} \mathrm{O}$ NPs dispersions with plant extract, which is depicted in Fig. 5. As it is seen from the plot, the isoelectric point (IEP) is found near $5.5 \mathrm{pH}$. This implies that the dispersion is stable below $5.0 \mathrm{pH}$ and above $6.0 \mathrm{pH}$ of the medium.

We have used XPS measurement to study the interfacial interaction between oxide NP and saponin molecules and to find the chemical state of copper $(\mathrm{Cu})$ atom in synthesized NPs. Fig. 6 depicts the XPS spectrum recorded of $2 p$ photoelectrons of $\mathrm{Cu}(\mathrm{A})$ with

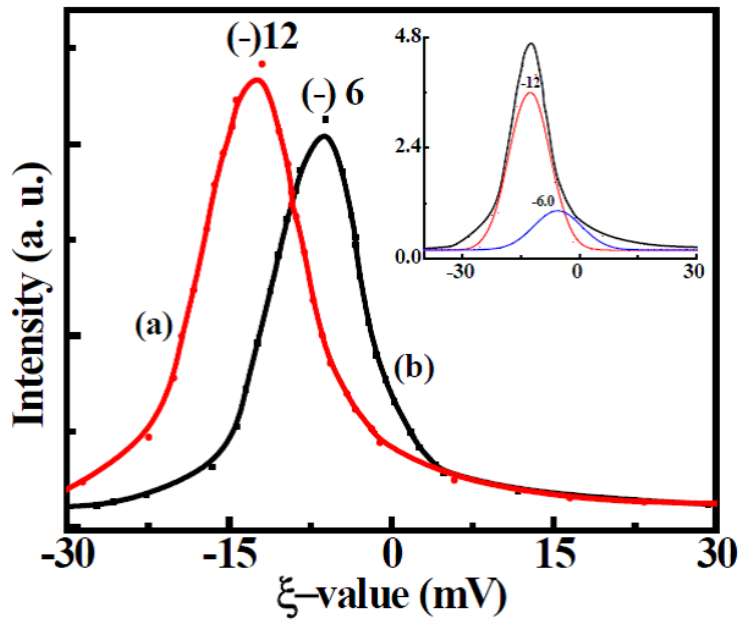

Fig. 4. Zeta potential band of $\mathrm{Cu}_{2} \mathrm{O}$ NPs: (a) with and (b) without plant extract. The inset shows deconvolution of (a) into two overlapping bands.

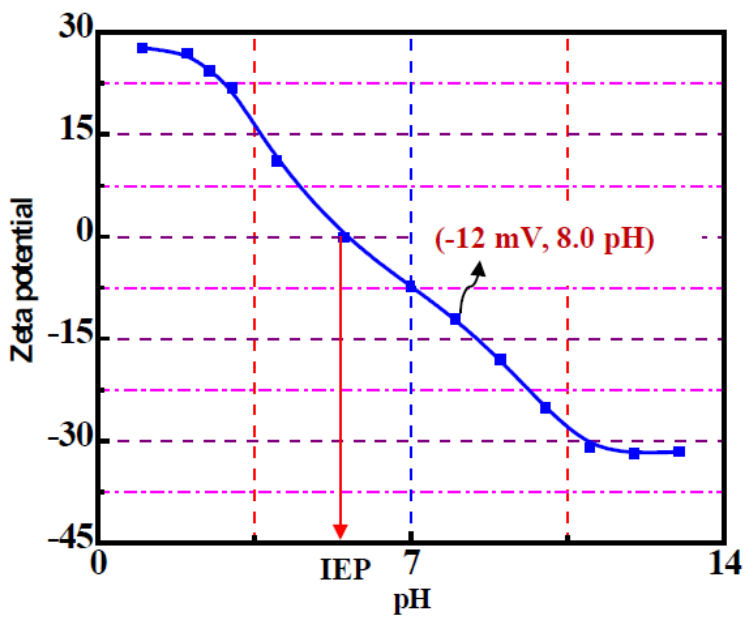

Fig. 5. Variation of zeta potential with $\mathrm{pH}$ of $\mathrm{Cu}_{2} \mathrm{O}$ NPs with plant extract.

and (B) without saponin molecules. The XPS spectrum detects a doublet for $\mathrm{Cu} 2 \mathrm{p}$ band, i.e. $\mathrm{Cu}^{2} \mathrm{p}_{3 / 2}$ and $\mathrm{Cu}^{2} \mathrm{p}_{1 / 2}$ at 932.5 and $952.5 \mathrm{eV}$, respectively. In sample $\mathrm{B}$, the deconvolution of $\mathrm{Cu} 2 \mathrm{p}$ doublet band-group shows one main band at binding energy (BE) of $932.5 \mathrm{eV}$ that is accompanied by satellite peaks on high BE side, 934.6, 940.3, and $943.1 \mathrm{eV}$, respectively. The band at $932.5 \mathrm{eV}$ is assigned for $\mathrm{Cu}^{2} \mathrm{p}_{3 / 2}$ peak of $\mathrm{Cu}^{+}$ion, whereas the shake-up satellite peaks come from $\mathrm{Cu}^{2+}$ state $[2,22]$. In sample A, the XPS spectrum shows a doublet for $\mathrm{Cu} 2 \mathrm{p}$ band, i.e. 
$\mathrm{Cu}^{2} \mathrm{p}_{3 / 2}$ and $\mathrm{Cu}^{2} \mathrm{p}_{1 / 2}$ at 932.1 and $952 \mathrm{eV}$, respectively. Decrease in $\mathrm{BE}$ of both $2 \mathrm{p}_{3 / 2}$ and $2 \mathrm{p}_{1 / 2}$ band in $\mathrm{Cu}_{2} \mathrm{O}$ with saponin molecules as compared to bulk $\mathrm{Cu}$ atom reveals a charge transfer interaction between NP and saponin surfactant molecules [17, 23-25].

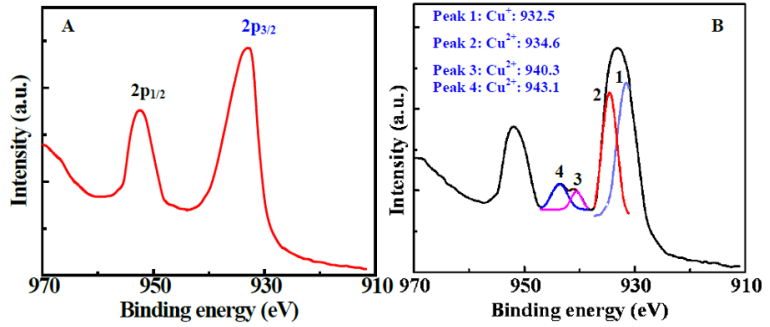

Fig. 6. XPS spectra of $\mathrm{Cu}_{2} \mathrm{O}$ nanocrystals: (A) with and (B) without plant extract (Peak 1 - light blue, Peak2 - red, Peak3 - pink, and Peak4 - blue).

\subsection{Microstructural analysis}

The size, shape, and distribution of saponinencapsulated oxide NPs can be studied with high resolution TEM image. Fig. 7a depicts a TEM image obtained from saponin capped NPs. Nearly spherical nanoclusters of an average 120 to $150 \mathrm{~nm}$ diameter are seen in this image. As the adsorbed layer has a thickness less than $1 \mathrm{~nm}$ and is of very light in contrast, it is hardly noticeable in the HRTEM image. A lattice plane distance of $0.245 \mathrm{~nm}$ (as shown in Fig. 7b) corresponds to (111) plane of fcc $\mathrm{Cu}$-atom in cuprous oxide NP [26, 27].

\section{Mechanism of formation of saponin encapsulated $\mathrm{Cu}_{2} \mathrm{O}$ NPs}

In support of experimental findings, we propose a stepwise path followed for the synthesis of saponin capped $\mathrm{Cu}_{2} \mathrm{O}$ NPs, which is illustrated in Fig. 8. Scheme 1A shows the synthesis of NPs, whereas Scheme 1B explains encapsulation of NP. As illustrated in Scheme 1A, at first the precursor salt (i.e. $\mathrm{CuSO}_{4} \cdot 5 \mathrm{H}_{2} \mathrm{O}$ ) reacts with hydroxyl anion $(-\mathrm{OH})$ generated by reaction between hydrazine $\left(\mathrm{NH}_{2} \mathrm{NH}_{2}\right)$ with water, forming copper hydroxide, i.e. $\mathrm{Cu}(\mathrm{OH})_{2}$ particles. Then, these particles react

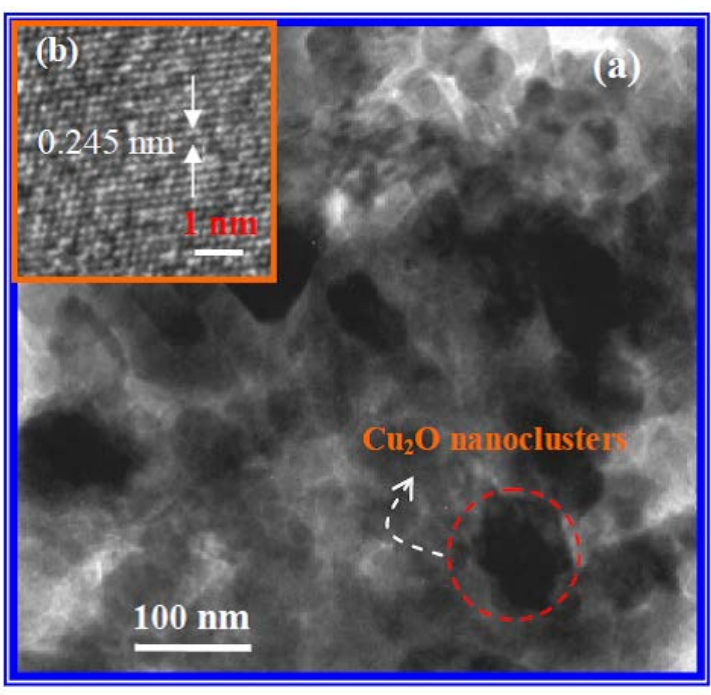

Fig. 7. HRTEM images of $\mathrm{Cu}_{2} \mathrm{O}$ nanoclusters with plant extract.

with $\mathrm{NH}_{2} \mathrm{NH}_{3}^{+}$in a dilute medium, giving $\mathrm{Cu}_{2} \mathrm{O}$ NPs and later, upon aggregation, forming a cluster owing to their high surface area to volume ratio. The encapsulating agent present in the plant extract encages the nanocluster via nonbonding electrons of $-\mathrm{OH}$ groups to give a thin inert layer over it, as depicted in the Scheme 1B.

\section{Conclusions}

Phase-pure $\mathrm{Cu}_{2} \mathrm{O}$ NPs were synthesized in presence of a bio-surfactant using hydrazine hydrate as reducing agent in an aqueous medium. UV-Vis spectrum and XRD pattern confirms formation of $\mathrm{Cu}_{2} \mathrm{O}$ NPs. Red-shift in the $\mathrm{Cu}-\mathrm{O}$ stretching vibrational band in presence of plant extract confirms surface interaction between $\mathrm{Cu}_{2} \mathrm{O}$ NP and bio-surfactant. Negative zeta potential and chemical shift in $\mathrm{Cu} 2 \mathrm{p}$ band of saponin capped oxide NP relative to $\mathrm{Cu}_{2} \mathrm{O}$ suggests accumulation of non-bonding electrons (i.e. O-atom of $-\mathrm{OH}$ group) of saponin on the surface of $\mathrm{Cu}_{2} \mathrm{O}$ NP. Possible mechanism of formation of saponin encapsulated $\mathrm{Cu}_{2} \mathrm{O}$ NPs is proposed in support of the experimental findings. Phase-pure $\mathrm{Cu}_{2} \mathrm{O}$ NPs could be a promising material for various applications, such as water treatments, photocatalysis, gas sensing, and photovoltaics. 
(A) Synthesis of $\mathrm{Cu}_{2} \mathrm{O}$ NPs

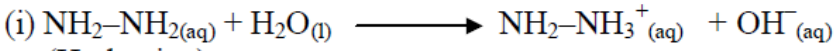
(Hydrazine)

(Hydrazine in water produces hydroxyl anion)

(ii) $\mathrm{CuSO}_{4} .5 \mathrm{H}_{2} \mathrm{O}+2 \mathrm{OH}-\mathrm{Cu}(\mathrm{OH})_{2}+\mathrm{SO}_{4}{ }^{2-}+5 \mathrm{H}_{2} \mathrm{O}$

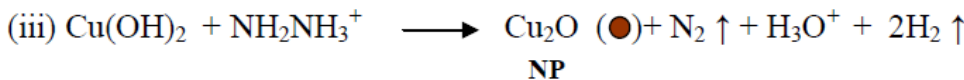

(B) Encapsulation of $\mathrm{Cu}_{2} \mathrm{O}$ nanocluster by saponin molecules
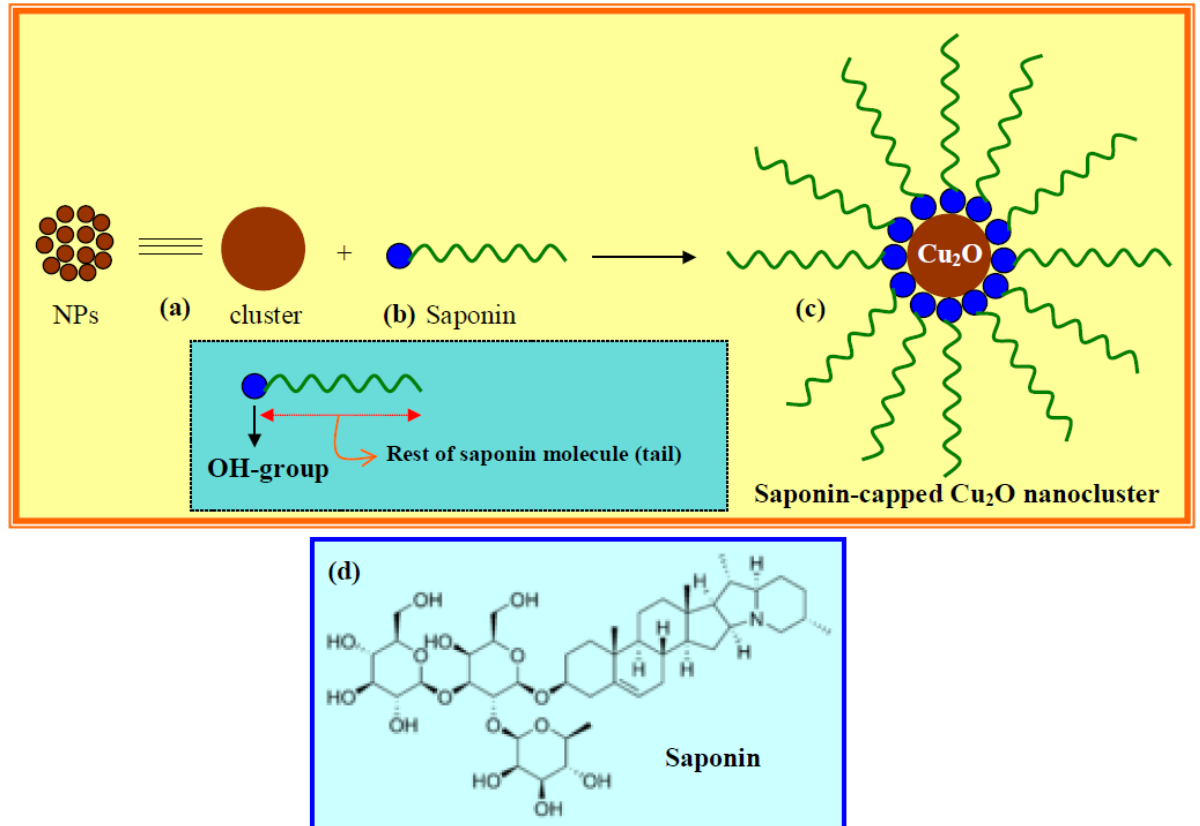

Fig. 8. Scheme of synthesis of NPs (A) and encapsulation of NP (B).

\section{Acknowledgements}

Financial support of Silicon Institute of Technology is highly acknowledged.

\section{References}

[1] YAng M., ZHU J., J. Cryst. Growth, 256 (2003), 134.

[2] Yin M., Wu C., Lou Y., Burda C., Koberstein J., Zhu Y., O’Brien S., J. Am. Chem Soc., 127 (2005), 9506.

[3] Saito G., Hosokai S., Tsubota M., Akiyama T., J. Appl. Phys., 110 (2011), 023302.
[4] Abboud Y., Saffaz T., Chagraoui A., El Bouari A., Brouzi K., Tanane O., Ihssane B., Appl. Nanosci., DOI: 10.1007/s13204-013-0233-x.

[5] Sahoo S., Husale S., Colwill B.,Toh-Ming L.T., NAYAK S., AJAYAN P.M., ACS Nano, 3 (2009), 3935.

[6] Kuo C., Huang M. H., J. Phys. Chem. C, 112 (2008), 18355.

[7] Singh D.P., Neyi N.R., Sinha A.S.K., SRIVAStaVA O.N., J. Phys. Chem. C, 111 (2007), 1638.

[8] Zhao H.Y., Wang Y.F., Zeng J.H., J. Cryst. Growth, 8 (2008), 3731. 
[9] Ramesh C., Hariprasad M., Raghunathan V., Curr. Nanosci., 7 (2011), 995.

[10] Stanimirova R., Marinova K., TCholakova S., Denkov N.D., Stoyanov S., Pelan E., Langmuir, 27 (20) (2011), 12486.

[11] Donnan F.G., Thomas J.S., J. Chem. Soc. Trans., 99 (1911), 1788.

[12] He P., Shen X., Gao H., J. Colloid Interf. Sci., 284 (2005), 510.

[13] Qingde Chen Q., Xinghai Shen S., Hongcheng GAO H., J. Colloid Interf. Sci., 312 (2007), 272.

[14] Burda C., Chen X., Narayanan R., El-Sayed M.A., Chem. Rev., 105 (2005), 1025.

[15] Salem A.M., Selim M.S., SAlem A.M., J. Phys. D Appl. Phys., 34 (2001), DOI: 10.1088/00223727/34/1/303.

[16] Zhu Q., Zhang Y., Wang J., Zhou F., ChU P.K., J. Mater. Sci. Technol., 27 (2011), 289.

[17] Behera M., RAM S., Appl. Nanosci., DOI: 10.1007/s13204-012-0159-8.

[18] Mahajan M.B., Pavan M.S., Joy P.A., Solid State Commun., 149 (2009), 2199.
[19] Zhang D.-F., Zhang H., Guo L., Zheng K., HAN X.-D., Zhang Z., J. Mater. Chem., 19 (2009), 5220.

[20] Behera M., RAM S., Int. Nano. Lett., 3 (2013), 17.

[21] Behera M., Ram S., Appl. Nanosci., 3 (2013), 83.

[22] Ghodselahi T., Vesaghi M.A., Shafiekhani A., Baghizadeh A., Lameit M., Appl. Surf. Sci., 255 (2008), 2730.

[23] Abyaneh M.K., Parmanik D., Varma S., Gosavi S.W., Kulkarni S.K., J. Phys. D Appl. Phys., 40 (2007), 403771.

[24] Tripathy P., Mishra A., Ram S., Fecht H.J., BANSMANN J., BEHM R.J., Nanotechnology, 20 (2009), 075701.

[25] Behera M., RAM S., Appl. Nanosci., DOI: 10.1007/s13204-013-0198-9.

[26] Huang W.C., LyU L.M., Yang Y.C., HuAng M.H., J. Am. Chem. Soc., 134 (2012), 1261.

[27] Kuo C.H., Huang M.H., J. Am. Chem. Soc., 130 (2008), 12815.

Received 2014-07-03 Accepted 2014-09-29 